SLAC-PUB-8130

April 1999

\title{
The Next Linear Collider Machine Protection System
}

By C. Adolphsen et al.

Presented at IEEE Particle Accelerator Conference (PAC 99), 3/29/99ã4/2/99, New York, NY, USA 


\title{
THE NEXT LINEAR COLLIDER MACHINE PROTECTION SYSTEM *
}

\author{
C. Adolphsen, J. Frisch, R.K. Jobe, D. McCormick, W.R. Nelson, T.O. Raubenheimer, S. Rokni,
}

M.C. Ross", P. Tenenbaum, D.R. Walz,

Stanford Linear Accelerator Center, Stanford, CA, 94309.

\section{Abstract}

The Next Linear Collider (NLC) electron and positron beams are capable of damaging the linac accelerating structure and beamline vacuum chambers during an individual aberrant accelerator pulse. Machine protection system (MPS) considerations, outlined in this paper for the $1 \mathrm{TeV}$ NLC design, have an impact on the engineering and design of most machine components downstream of the damping ring injector complex. The MPS consists of two functional levels. The first level provides a benign, single bunch, low intensity, high emittance pilot beam that will be used for commissioning and also whenever the integrity or the settings of the downstream components are in doubt. This level also provides for the smooth transition back and forth between high power operation and the benign diagnostic pilot bunch operation. The pilot bunch parameters in the main linac are estimated on the basis of the expected stress in the accelerator structure copper. Beam tests have been done at the SLAC linac to examine the behavior of the copper at the damage stress threshold. Typical pilot beam parameters (compared with nominal) are: 10 times reduced intensity, 10 times increased horizontal emittance and 1000 times increased vertical emittance, resulting in a reduction in charge density of $10^{5}$. The second level is the primary protection against a single aberrant pulse. Its goal is to reduce the possibility that a substantial transverse field changes the trajectory of the high power beam from one pulse to the next. All devices that could produce such a field are 1) monitored by a fast response network and where possible have 2) deliberately slowed response times. A 'maximum allowable interpulse difference' is evaluated for each such device as well as the beam trajectory monitors in each interpulse period.

\section{INTRODUCTION}

The purpose of the MPS[1] is to provide machine components with a reasonable level of protection from damage caused by the beam. Because of its high charge $(150 \mathrm{nCb})$ and very small cross-sectional area $(7 \times 1 \mu \mathrm{m})$, a single full intensity NLC [2] pulse can badly damage any physical object, including the main linac copper diskloaded waveguide structure, if allowed to strike it directly. The MPS must provide the tools to 1) allow the beam power to be raised to the nominal following an interruption and the tools to 2) sustain nominal power operation. This paper describes the determination of the pilot bunch parameters, the pulse sequence transition to full power, and the monitoring needed to sustain full power operation.

\section{PILOT BEAM}

It is obvious that NLC operation cannot be initiated with high power pulses; the first pulse to traverse the linac must be one without the capability to damage the structure. Indeed, following any time interval large enough to allow a substantial change in the beam trajectory or component alignment $(\sim$ a fraction of a second), the pilot beam must be used to prove the integrity of the system before allowing high power operation to resume. This means that high intensity, low repetition rate is not allowed.



Figure 1: Predicted [3] maximum temperature rise in the irises of the NLC X-band accelerating structure as a function of distance for the nominal $10^{12}$ particles/pulse at $500 \mathrm{GeV}$. The estimate does not account for possible cooling that might occur during the inter-bunch interval (1.4 or $2.8 \mathrm{~ns}$ ). The horizontal dashed lines indicate the melting point and the expected thermal stress limit in fully annealed copper.

\subsection{Single Pulse Structure Damage}

We expect that the threshold charge density for structure damage is well below the point at which the material actually melts. Substantial crystalline grain growth and

\footnotetext{
* Work supported by the U.S. Department of Energy under Contract No. DE-AC03-76SF00515.

\#Email: mcrec@slac.stanford.edu
} 
possible fracture should be observed at the point where the deposited heat causes local stresses beyond the tensile limit. This is expected to occur a threshold $\Delta \mathrm{T}$ of $180^{\circ} \mathrm{C}$.

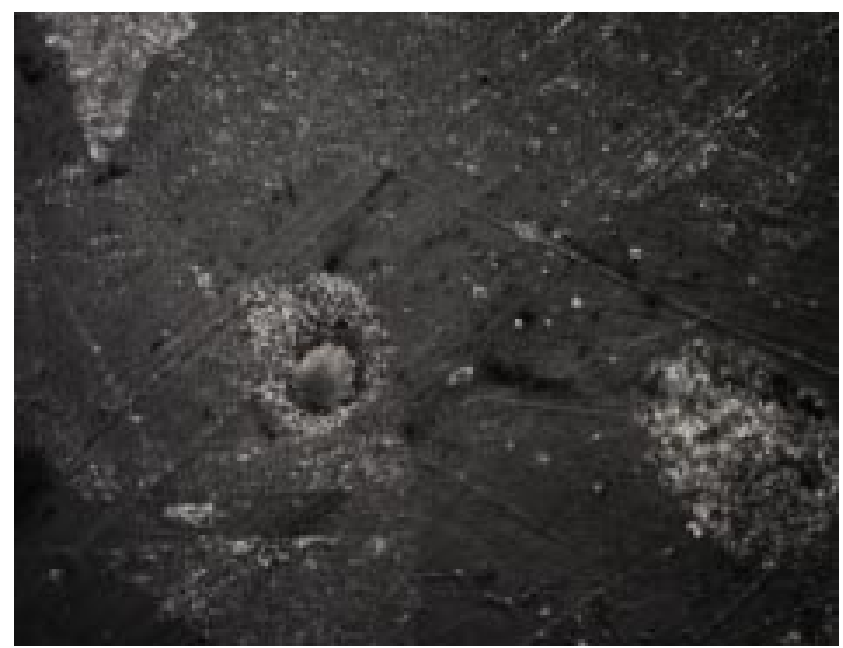

Figure 2: An optical microscope picture (500x) of the back side of the $1.4 \mathrm{~mm}$ thick copper iris sample following a single hit by a $10^{10}, \sigma_{\mathrm{x}, \mathrm{y}}=15 \mu \mathrm{m}$ round beam, $\Delta \mathrm{T} \sim 1000{ }^{\circ} \mathrm{C}$. A small melted spot, about $10 \mu \mathrm{m}$ wide, is easily seen.

Figure 1 shows the estimated maximum temperature rise in the structure following a hit from a misdirected beam. The peak temperature is expected either at the rear surface of the structure cut-off iris (located at either end) or several disks following the disk first hit by the beam. In Table 1, proposed pilot beam parameters, (steps numbered 1, with options 1.1 and 1.2), have been set so as to limit the maximum accelerator disk temperature rise to $180^{\circ} \mathrm{C}$, $0.036 \mathrm{pCb} / \mu \mathrm{m}^{2}$ at $500 \mathrm{GeV}$. Pilot beam step 1 shows the limiting intensity at an emittance $\varepsilon_{\mathrm{X}}\left(=\varepsilon_{\mathrm{y}}\right) \sim 10 \varepsilon_{\mathrm{x}}$ nominal, step 1.1 shows the limiting intensity with the NLC damping rings operating on the coupling resonance $\left(v_{x}=v_{y}\right)$ and step 1.2 shows the limiting emittance at nominal $N L C$ bunch intensities, (in this case, $\varepsilon_{\mathrm{x}, \mathrm{y}}>$ injector emittance of 7e-5 m-rad).

\subsection{Beam Test Results}

In order to validate both the calculations shown in Figure 1 and our estimate of the impact on the structure material, we have done a beam test in the Final Focus Test Beam [4] at SLAC, where small, high charge density pulses can be focused onto a target sample. In the test, a sample similar to a single disk-loaded waveguide iris was subjected to single pulses of a $28.5 \mathrm{GeV}$ e- beam. The intensity and size of the beam were varied over the ranges of interest. At present, we are in the process of examining the damage observed on the back side of the sample. Figure 2 shows a typical melted spot from a single beam pulse as seen using an optical microscope.

\section{TRANSITION TO FULL POWER}

Once the pilot beam operation is satisfactory, the NLC MPS will allow the production of a high power beam. Table 1 shows the progression of steps that occur in the transition from 1) pilot, to 2) nominal single bunch intensity, to 3) nominal emittance and finally to 4) the nominal number of bunches $n_{b}=95$. During the pilot bunch operation and the transition, the emittance is increased by introducing a vertical dispersion or coupling bump in the main damping ring; the intensity is reduced at the source.

The MPS includes subsystems that make sure that the performance of the high power beam is close enough to that of the pilot beam throughout and also following transitions in either direction. Care must be taken to feedforward to those devices whose equilibrium performance (e.g. temperature) depends on the beam power, such as the highly loaded accelerating structures.

Also, during the sequence, care must be taken to allow time for beam-based feedback systems to properly close. This is required not so much because of the need to control single aberrant pulses but because of the requirement to limit fractional losses of the beam in given locations. This 'average power' limiting MPS is commonly used in high power linacs [5]. Reference

Table 1: Linac MPS Transition Sequence from pilot beam to nominal full power operation. Only step 4 has $\mathrm{n}_{\mathrm{b}}>1$. The peak charge density $\rho$ is computed using $2 \pi \sigma_{\mathrm{x}} \sigma_{\mathrm{y}}$ as the peak density. The beam sizes, $\sigma_{\mathrm{x}}$ and $\sigma_{\mathrm{y}}$ are estimated using the linac quadrupole magnet spacing and the optical phase advance to estimate the geometric mean $\left(\sqrt{ } \beta_{\mathrm{x}} \beta_{\mathrm{y}}\right)$. Step 4.1 shows parameters associated with the $\mathrm{n}_{\mathrm{b}}=190,1.4 \mathrm{~ns}$ inter-bunch time operation.

\begin{tabular}{|c|c|c|c|c|c|c|c|c|c|}
\hline $\begin{array}{l}\text { Step } \\
\#\end{array}$ & $\begin{array}{l}\text { I/pulse } \\
\text { e } \pm / \text { pulse }\end{array}$ & $\begin{array}{c}\gamma \varepsilon_{\mathrm{X}, \mathrm{y}} \\
(\mathrm{m}-\mathrm{rad})\end{array}$ & $\begin{array}{l}\sigma_{\mathrm{x}} \sigma_{\mathrm{y}} \\
\text { begin } \\
\left(\mu \mathrm{m}^{2}\right)\end{array}$ & $\begin{array}{l}\sigma_{x, y} \text { begin } \\
(\mu \mathrm{m})\end{array}$ & $\begin{array}{l}\rho \text { begin } \\
\mathrm{pCb} / \mu \mathrm{m}^{2}\end{array}$ & $\begin{array}{l}\sigma_{\mathrm{x}} \sigma_{\mathrm{y}} \\
\text { end } \\
\left(\mu \mathrm{m}^{2}\right)\end{array}$ & $\begin{array}{l}\sigma_{\mathrm{x}, \mathrm{y}} \text { end } \\
(\mu \mathrm{m})\end{array}$ & $\begin{array}{l}\rho \text { end } \\
\mathrm{pCb} / \mu \mathrm{m}^{2}\end{array}$ & $\begin{array}{l}\Delta \mathrm{T} \max \\
\left({ }^{\circ} \mathrm{C}\right)\end{array}$ \\
\hline 1 & $1.1 \mathrm{E}+09$ & $3.0 \mathrm{E}-05$ & 13,000 & 110 & .0022 & 780 & 28 & .036 & 180 \\
\hline 1.1 & $0.70 \mathrm{E}+08$ & $1.5 \mathrm{E}-06$ & 650 & 26 & .0022 & 39 & 6.2 & .036 & 180 \\
\hline 1.2 & $1.0 \mathrm{E}+10$ & 2.7E-04 & 117,500 & 340 & .0022 & 7016 & 84 & .036 & 180 \\
\hline 2 & $1.0 \mathrm{E}+10$ & $3.0 \mathrm{E}-05$ & 13,000 & 110 & .019 & 780 & 28 & .36 & 1800 \\
\hline \multicolumn{10}{|c|}{$\gamma \varepsilon_{\mathrm{x}} \gamma \varepsilon_{\mathrm{y}}$} \\
\hline 3 & $1.0 \mathrm{E}+10$ & $3.0 \mathrm{E}-06$ & X $3.0 \mathrm{E}-08$ & $31.3 \times 4.4$ & 1.4 & 11.0 & $7.7 \times 1.1$ & 23 & $1.1 \mathrm{E}+05$ \\
\hline 4 & $9.0 \mathrm{E}+11$ & $3.0 \mathrm{E}-06$ & X $3.0 \mathrm{E}-08$ & $31.3 \times 4.4$ & 120 & 11.0 & $7.7 \times 1.1$ & 2100 & $1 \mathrm{E}+07$ \\
\hline 4.1 & $1.4 \mathrm{E}+12$ & $3.0 \mathrm{E}-06$ & X $3.0 \mathrm{E}-08$ & $31.3 \times 4.4$ & 190 & 11.0 & $7.7 \times 1.1$ & 3325 & $1.6 \mathrm{E}+07$ \\
\hline
\end{tabular}


[6] outlines a predictor system using a long ion chamber sensor.

\section{MAXIMUM ALLOWABLE INTERPULSE DIFFERENCE}

The maximum allowable interpulse difference (MAID) can be defined along the beamline and is determined by the structure and dynamics of the downstream system. It is the responsibility of the MAID system to guarantee that subsequent beam pulses all lie within an elliptical region centered near the present pulse. The MAID MPS primarily uses position monitor readings and device controller monitoring. Similar MPS are used at high current synchrotron light sources.

Since the NLC has a linear geometry, it is not possible to abort a pulse following its extraction from the damping ring. The trajectory of the previous pulse is compared to the MAID threshold and used to generate a permit for ring extraction. Typical linac MAID trajectory thresholds are $300 \mu \mathrm{m} x$ by $100 \mu \mathrm{m} y$.

Table 2 lists some critical devices that must be checked before ring extraction because they may change substantially during the interpulse interval. A fault in the klystron / modulator pair primarily results in a small reduction in energy rather than a strong transverse kick, so the permit is based on a multiplicity count that allows several of them to fault on a given pulse. The minimum practical time for the polling to occur is about $100 \mu$ s before ring extraction. The devices listed in Table 2 must be engineered such that the chance that failure not signalled by the fast polling network is very small.

Table 2: Examples of main linac devices which are checked just before damping ring extraction. The Response/ Sensor indicates steps taken in the design to reduce the risk of this failure.

\begin{tabular}{|l|l|l|}
\hline Device & Problem & Response/ Sensor \\
\hline $\begin{array}{l}\text { Klystron/ } \\
\text { Modulator }\end{array}$ & $\begin{array}{l}\text { Internal interlock } \\
\text { trip }\end{array}$ & $\begin{array}{l}\text { Compare with } \\
\text { allowed } \\
\text { multiplicity }\end{array}$ \\
\hline Magnet & $\begin{array}{l}\text { Cable/magnet } \\
\text { failure }\end{array}$ & $\begin{array}{l}\text { Monitor voltage/ } \\
\text { current }\end{array}$ \\
\hline Mover & Runaway & $\begin{array}{l}\text { Designed to be } \\
\text { slow }\end{array}$ \\
\hline Timing & $\begin{array}{l}\text { Distribution } \\
\text { failure }\end{array}$ & $\begin{array}{l}\text { Designed to be } \\
\text { redundant }\end{array}$ \\
\hline $\begin{array}{l}\text { Control } \\
\text { system }\end{array}$ & $\begin{array}{l}\text { Loss of } \\
\text { connection }\end{array}$ & Redundancy \\
\hline
\end{tabular}

In order to limit the list as much as possible, we have segmented the NLC into three sections using high power collimation that prevents the passage of a pulse with excursions large enough to strike the downstream section. The segmentation separates the linac, with its small number of different kinds of components, from the upstream damping ring and first bunch compressor and from the downstream beam delivery.

High power collimation of such small beams at 500 $\mathrm{GeV}$ and higher energies remains to be designed. The performance of the collimators will determine the MAID limits in the linac and set MPS parameters in that segment of the NLC.

\section{CONCLUSIONS}

The NLC MPS affects the design of most components ranging from beamline vacuum chambers to high power devices and their controls. An integrated system is needed to provide smooth operation with a minimum of false alarms. The proposed MPS builds on experience at SLAC and other large, high intensity machines to achieve this, although this is the first application of the pilot beam with an intensity and emittance transition sequence.

\section{ACKNOWLEDGEMENTS}

We would like to acknowledge the help of R. Kirby and J. Francis in the analysis of the copper coupon and the help of the SLAC linac operations staff in the operation of the FFTB test. We would also like to acknowledge the help of C. Field and Y-Y. Sung in the preparation of the coupon test.

\section{REFERENCES}

[1] M. Ross, "Machine Protection Schemes for SLC", Proc. PAC91, 1502 (1991)

[2] NLC ZDR Design Group, "Zeroth-Order Design Report for the Next Linear Collider", SLAC Report 474, (1996). Updated parameters can be found on the NLC Accelerator Physics Web pages at http://www-project.slac.stanford.edu/lc/nlc-tech.html.

[3] W.R.Nelson, H.Hirayama and D.W.O. Rogers, "The EGS4 Code System”, SLAC Report 265, (1985).

4 ] V.A. Alexandrof et al, "Results of Final Focus Test Beam," Proc. PAC95, 2742 (1995).

[5] S. Clark et al, "Smart Machine Protection System", Proc. ICALEPS91, 420 (1991).

[6] M.C. Ross and D. McCormick, "A Coaxial Cable Beam Loss Monitor Ion Chamber System for High Power Multibunch Beams", Proc. LINAC98, (1998). 